\title{
Biblioteca Fundamentos de la Construcción de Chile: construir la nación por medio de la ciencia
}

\author{
Biblioteca Fundamentos de la Construcción de Chile: \\ building the nation by means of science
}

\author{
Jorge Muñoz Sougarret \\ Professor, Centro de Estudios del Desarrollo Local y Regional/Universidad de Los Lagos. \\ munozsougarret@yahoo.es
}

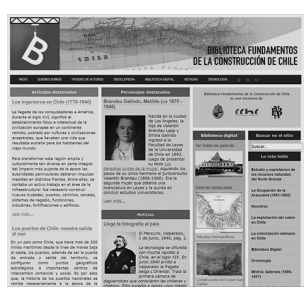

Biblioteca Fundamentos de la Construcción de Chile. http://www. bibliotecafundamentos.cl

G $\mathrm{n}$ el marco de la celebración del bicentenario independentista Een Chile, la Pontificia Universidad Católica, la Dirección de Bibliotecas, Archivos y Museos y la Cámara Chilena de la Construcción (la mayor multigremial empresarial del país) se reunieron para impulsar la publicación de cerca de un centenar de textos producidos por los primeros científicos del país (técnicos, ingenieros y profesionales de las diversas ramas), en un marco temporal que abarca la segunda mitad del siglo XIX y las primeras décadas del siglo XX. Reedición, que acompañada por nuevos prólogos, hoy es posible de consultar íntegramente en una página web creada especialmente (www. bibliotecafundamentos.cl), en su sección biblioteca digital. La riqueza de esta propuesta supera con creces la simple idea de la reedición de textos fundamentales para investigar sobre el imaginario científico del Chile decimonónico, aportando elementos para poder estudiar las bases de la construcción de Chile (como nos lo proponen sus editores).

Para reconocer la riqueza histórica de la recopilación debemos comprender históricamente las motivaciones originales de sus autores por intentar escribir ciencia desde Chile, para los chilenos y el mundo, sin embargo ser muchos de ellos científicos o profesionales extranjeros con asiento provisional en el país. Sin temor a equivocarnos, sus motivaciones personales fueron condicionadas por las obsesiones políticas de la época; en gran medida forjadas a la vera del camino bélico emprendido por Chile durante la tercera década de siglo XIX. El triunfo de las facciones conservadoras en la política interna de Chile, a principios de la década, propició la posibilidad de imaginar al país ya no como un espacio menor y alejado de los circuitos comerciales e intelectuales de América. La relativa calma política forjó la idea de la "excepcionalidad" chilena, a la luz de las frecuentes guerras civiles que desangraban a los países del Cono Sur americano, aquella tesis se vio reforzada cuando se emprendió la guerra preventiva contra la Confederación Perú-Boliviana, entre 1837 y 1839, que finalizó con la victoria chilena. 
No obstante ser rechazada la guerra en un primer momento por la población, el inesperado triunfo produjo una euforia bélica que instaló el germen de una identificación positiva con la Nación, a nivel individual y social. Los dirigentes del Estado se encontraron, durante la resaca de la euforia, con la incómoda pregunta sobre qué significaba la Nación y cuáles eran sus potencialidades y límites. Impulsándoles a emprender una nueva guerra contra la propia ignorancia, decidiéndose a emplear a un sinnúmero de científicos y profesionales extranjeros para desarrollar la ciencia en el país. Científicos que arribaron al país imbuidos de una concepción humanista de la ciencia, ya que creían ver en ella una obra dirigida a todos los colectivos humanos, sin distinción de regiones o culturas - estableciéndose los primeros conceptos científicos para nombrar a los individuos y su interrelación con el ambiente, como fueron el "cosmos" de Humboldt o la "humanidad" de Herder.

Nada debía quedar fuera de su vista, nadie debía obstaculizar su trabajo, mucho menos la cultura o la religión. Estos primeros extranjeros se transformaron en las aulas en los forjadores de una nueva generación de chilenos, convencidos de su rol como divulgadores de la nacionalidad vía la ciencia. Haciendo en el futuro indisoluble esta unión, a tal punto de ser el pilar fundamental que impulsó la siguiente empresa bélica exterior de Chile, nuevamente contra Perú y Bolivia, e interior, contra las comunidades indígenas de la Araucanía; ambas sostenidas bajo la égida de la ciencia, el progreso y la Nación.

Así como la guerra había gestado la simiente del nacionalismo, también había impulsado a la ciencia como la herramienta de construcción y conservación del nacionalismo a lo largo del tiempo. Certeza que fue puesta en duda durante las celebraciones del primer centenario patrio, terminando por trastabillar durante la Primera Guerra Mundial; sin embargo aquella es otra historia y, con razón, se aleja temporalmente del fin de la recopilación que comentamos.

Si en los párrafos previos nos referimos a la amplitud de miradas sobre Chile, consideramos que la reedición que reseñamos demuestra nuestra afirmación de manera cabal. Se inicia con el extenso trabajo de Claude Gay, que transitó desde la botánica hasta la historia, seguido por el lúcido trabajo de Julio Menadier sobre las potencialidades de la agricultura; visión que era complementada por los impulsores de la pesca y silvicultura (como Federico Albert) y la minería metálica y carbonífera (representada por Carlos Vattier, Santiago Macchiavelo, Alejandro Bertrand, Guillermo Billinhurst, Enrique Álvarez y Marcial Aracena). En contraposición a los anteriormente citados, aparecen los textos de los críticos al desarrollo en base a compartimientos económicos, divididos en cuatro grupos; primeramente se encontraban los que proponían que la ruta de Chile debía ser la industrialización de su economía, según el modelo del Atlántico norte (en esta línea son los libros de Román Espech, Matías Rojas y Reinaldo Harnecker). Un segundo grupo hablará de la necesidad de modificar el Estado, para hacerlo transitar hacia una institucionalidad que permita la liberalización de las trabas legales para invertir en la economía del país (en este se cuentan Andrés Bello, Diego Benavente, Matilde Brandau y Edwin Kemmerer). Terceros, en este coro de corifeos, aparecen los defensores de la educación como mecanismo previo al desarrollo económico del país; invocando la máxima que un pueblo educado sabrá defender de mejor formas los triunfos del progreso, la ciencia y la Nación (representados, en esta recopilación, por Domingo Faustino Sarmiento, Gabriela Mistral, José Núñez y Eloisa Díaz). En último término, surgen las ácidas voces que increpan a todos sus pares por olvidarse de los sectores desposeídos del país, 
aquellos que fueron abandonado por la ciencia y la Nación (siendo sus autores más influyentes Darío Salas, Amanda Labarca, Alejandro Venegas y Alberto Cruchaga, posteriormente San Alberto Hurtado). Opinión que era compartida por ciertos sectores médicos, que buscaron una explicación clínica al decaimiento moral y físico de los sectores desposeídos (Eduardo Cruz-Coke y Ludwig Drapsky).

La visión económico-moral propuesta por nuestros autores se vio complementada con el estudio territorial de Chile, desde su geografía y botánica, hasta la descripción descarnada de las poblaciones nativas; en esta sección destacan los bellos trabajos de Guillermo Cox, Rodulfo Phillipi, Ignacio Domeyko, Francisco Vidal Gormáz y Karl Reiche, en los cuales se puede palpar la cercanía de la ciencia con la admiración - al momento de enfrentarse, en este caso, con el desconocido mundo de los indígenas. En sus antípodas aparecen los trabajos que se centran en el estudio urbano de la Nación, destacando la necesidad de las nuevas tecnologías como mecanismo de corregir los nacientes problemas sociales e higiénicos de las urbes (seleccionándose los escritos de Carlos Carvajal, Camilo Cordemoy y Alberto Fagalde). Finalmente, pero no menos importantes, emergen variados informes que llaman a las autoridades nacionales a poner atención en la necesidad de fortalecer las rutas y mecanismos de intercambio a nivel interior como exterior; vislumbrando, correctamente, que el desarrollo de la economía chilena correría de la mano de su integración con los mercados exteriores demandantes de materias primas (profética que nació de la pluma de Benjamín Vicuña Mackenna, Julio Pérez Canto, Allan Campbell y Santiago Marín).

Los tres editores de esta colección de libros supieron plasmar en la selección los más ambiciosos proyectos de futuro jamás pensados para Chile y su población, y, por lo mismo, los más bellamente ingenuos de su generación. Esta recopilación muestra que cuando la Nación chilena era exclusivamente un continente administrativo para su población, fue la ciencia la que permitió crear una identidad nacional. En los párrafos introductorios hablamos de las obsesiones, pues bien para Chile su obsesión era el futuro; pero no cualquier futuro, sino el más luminoso, aquel que esperaba a los países que podían triunfar sobre sus propias debilidades. Ingenuos pueden llamarse estos escritos, más no falsos; en ellos se propone un camino hacia el progreso que, a la luz de la distancia, continúa siendo el pilar de los deseos de futuro de Chile (extracción ordenada de materias primas, desarrollo tecnológico y educacional de la población, junto con la utilización de las potencialidades económicas derivadas de la situación geográfica del país). También han resistido a los años las profundas críticas de este camino de futuro, que critican la deshumanización de los colectivos y las individualidades; críticas que aunque aparecen matizadas en la recopilación, se presentan como un bemol que aterriza a los más elucubrados textos. En síntesis una invaluable recopilación para todo investigador interesado en el desarrollo de la ciencia, la política social y la historia en el Cono Sur americano reciente.

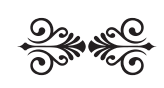

